\title{
The Use of Computers in Public and Private Primary Schools in Tanzania: A Digital Divide
}

\author{
Nestory Maro \\ School of Informatics \\ The University of Dodoma
}

\begin{abstract}
The existing scarcity of resources and challenges of getting reasonable education is necessitating communities to find new ways of tackling their problems. Education seems to be one of the best options to solve many of the problems facing communities. The collaboration of governments and primary sector in the provision of education has been of help in many countries across the world. The importance of the use of technology especially Information and Communication Technologies (ICTs) in education system in today's world is then unavoidable. This paper addresses the existing gap between Public and Private primary schools in Tanzania on the use of Information and Communication Technologies (ICTs), especially computers, in schools. The documentary review from various sources, and in specific Tanzanian Basic Education Statistics (BEST) reveals an inequality in the possession and use of computers among Public and private primary schools in Tanzania. In spite of the fact that the implementation of the use of ICT in schools is in phases, like infrastructures, curriculum and content, capacity building, procurement of hardware and software and some technical issues, efforts needs to be speeded up to make sure that the education system is inclusive. The primary education is the one that most of the citizens afford, and therefore should provide the necessary skill for citizens to compete in today's changing economy.
\end{abstract}

\section{General Terms}

ICT adoption, e-inclusion

\section{Keywords}

ICT for Education, Digital divide, ICT for Primary schools

\section{INTRODUCTION}

A good system of education in any country must be effective in two fronts: on the quantitative level to ensure access to education and equity in the distribution and allocation of resources to various segments of the society, and on the qualitative level, to ensure that the country produces the skills needed for rapid social and economic development. Evidence exists to show a very high correlation between investment in education and the creation of national wealth [4].

The Tanzanian National Education and Training policy of 1995 among other things puts emphasis on promoting access and equity through making access to basic education available to all citizens as a basic right; encouraging equitable distribution of educational institutions and resources; expanding and improving girl's education; screening for talented, gifted and disabled children so that they are given appropriate education and training, and developing programmes to ensure access to education to disadvantaged groups.
One of the most important factors in the education field today, other than good teachers, is Information, Communication \& Technology. The efficient \& effective use of ICT has enabled educationists worldwide to tackle challenges faced by students and teachers as well as to achieve excellence in education.

The gap between those able, and those unable, to participate in the knowledge economy is currently termed as the "digital divide." This digital divide is evident within nations, and between the developing and the developed world. The current Tanzania ICT situation requires urgent steps to enable Tanzanians to participate meaningfully in the knowledge economy, recognizing that Tanzania has low levels of human capital development, local content creation; ICT infrastructure and access, which together lead to high costs of participation.

The dangers posed by the digital divide, and the risk of being excluded further from the knowledge economy and social development, has propelled the Government to put in place a policy framework through which coordinating mechanisms and harmonized strategies might be nurtured. This policy framework makes it possible for "enabling sectors" (such as telecommunications, information, or broadcasting) to work together whereby "enabled sectors" (such as education, health, governance, or agriculture) can become further empowered through the appropriate development and application of ICT [4].

One of the objectives of the ICT policy in the country include creating appropriate employment and self-employment opportunities and related employment services for ICT and associated professions. These can be achieved through an the use and integration of ICT in building inclusive knowledge societies for all and for overall socio-economic development.

2. EDUCATION SYSTEM IN TANZANIA Tanzania education system follows a 7-4-2-3 system of education, preceded by a pre primary education, which seems an option. The Primary schooling takes seven years, followed by four years of secondary, two years of high school (advanced level), and three years of first degree university studies [3]. However some professions such as Engineering and Medicine take four to Five years. The media of instruction to all government primary schools is Kiswahili, the national language, with English taught as a subject from standard III to VII. On the other hand, there are other initiatives to ensure that those who missed this formal education are also involved in the education system. There is Adult education and Vocational training for those who wish to undertake some basic knowledge and technical expertise. 
According to the Tanzanian Education and Training policy of 1995, the role of Primary education among others include [4]

$\checkmark \quad$ To enable every child to acquire basic learning tools of literacy, communication, numeracy and problem solving as well as basic learning content of integrated relevant knowledge, skills and attitudes needed for survival and development to full capacity.

$\checkmark \quad$ To prepare the child to enter the world of work.

$\checkmark \quad$ To prepare the child for the second level education (secondary, vocational, technical and continuing education)

$\checkmark \quad$ To provide the child with the foundation of self initiative, self advancement and self confidence.

\subsection{ICT Policy}

There is an ICT policy [6] guiding all the ICT processes across the country with the aim of ensuring that Tanzania becomes a hub of ICT Infrastructure and ICT solutions that enhance sustainable socio economic development and accelerated poverty reduction both nationally and globally. However the, national ICT policy acts as a framework which leads all other policies related to the improvement of education sector such as the education sector development programme (ESDP) ensure that the two policies do not contradict.

The ICT policy [1] statements have been categorized into six areas for implementation as follows:

$\checkmark \quad$ Infrastructure and Technical Issues, these ensure that there are necessary platform to support the smooth implementation of the plan

$\checkmark$ Curriculum and Content, which

$\checkmark \quad$ Training and Capacity Building

$\checkmark$ Planning, Procurement and Administration

$\checkmark$ Management, Support and Sustainability

$\checkmark \quad$ Monitoring and Evaluation.

These phases have been implemented in the course of introducing computers in primary education. The curriculum is already in place and the instructors have been trained since the ICT subjects was introduced in the Teachers Colleges as part of equipping them with the skills necessary to teach at the lower levels.

\subsection{ICT in Schools}

In the last two decades, governments and educators all around the world have recognized or are coming to recognize the exceptional promise of ICT to foster teaching and learning in primary schools. However, it is important to note that for ICT to enhance teaching and learning, it needs to be supported by education and school policies and effective professional development for teachers [9].

In Tanzania, most private schools in the urban centers, especially Dar es Salaam, are already using ICTs, albeit without a formal setting or a policy framework. The impetus has come from parental pressure and the desire for students in these schools to achieve high national grades. However, even in these schools ICTs are mostly confined to administration. There is some limited use for teaching basic ICT skills; however, in most cases ICTs have not been integrated as a medium of instruction. Most of the activity is within the secondary school level, with negligible movement in primary and lower levels [4].

\subsection{Study Approach}

This study used a desk study approach by studying various documents related to the use of ICT in primary education. The Basic Education Statistics in Tanzania which are provided annually by Ministry of Education and Vocational Training (MoEVT) were used to illustrate the current situation.

\section{DATA PRESENTATION}

The data presented here have been extracted from the Basic Education Statistics (BEST) for the year 2012 released by the MoEVT, Tanzania mainland. These data should be regarded as illustrative rather than exhaustive, based on the time factor they were collected. However, they give a better illustration of the current situation in the use of Information and Communication Technology in Primary education in Tanzania.

\subsection{Number of Schools}

There has been an increase of the number of primary schools in the country over the years as shown in Table 1 below. The number of government schools has increased though with a small margin compared to the number of non government primary schools. The increase in the number of non government primary schools is witnessed in most of the urban areas across the country. Most of the government schools are located all over the country, almost every village or some streets have a government primary school. Some of non government schools are owned by individuals, Nonprofit Organizations and religious groups. These non government schools are located with specific focus such as the market niche or where these groups have interest. The non government schools have witnessed a sharp increase of $36.8 \%$ in the year 2012 .

Table 1: Number of schools

\begin{tabular}{lccccc}
\hline \hline Year & 2008 & 2009 & 2010 & 2011 & 2012 \\
\hline Gov & 15,673 & 15,727 & 15,816 & 16,001 & 16,331 \\
\% increase & 0.9 & 0.3 & -0.2 & 1.0 & 0.7 \\
Non Gov & 416 & 426 & 551 & 589 & 806 \\
\% increase & 28.4 & 2.4 & 29.3 & 6.9 & 36.8 \\
Total & 154,895 & 157,185 & 165,856 & 175,449 & 180,987 \\
\hline \hline
\end{tabular}

\subsection{Primary School Enrollment}

The enrollment to primary schools has been fluctuating over the years as shown in figure 1 . There was a slight decrease in enrolment (1.4\%) from 8,363,386 pupils in year 2011 to $8,247,172$ pupils in year 2012 . The decrease in enrolment is contributed by dropout whom increases as you go along from lower grade to upper grade. Hence sensitization is needed for pupils' retention. This enrollment is high to government schools compared to that of non government. Most of the students enrolled are of the age of 7 , with few below 7 years [11]. 


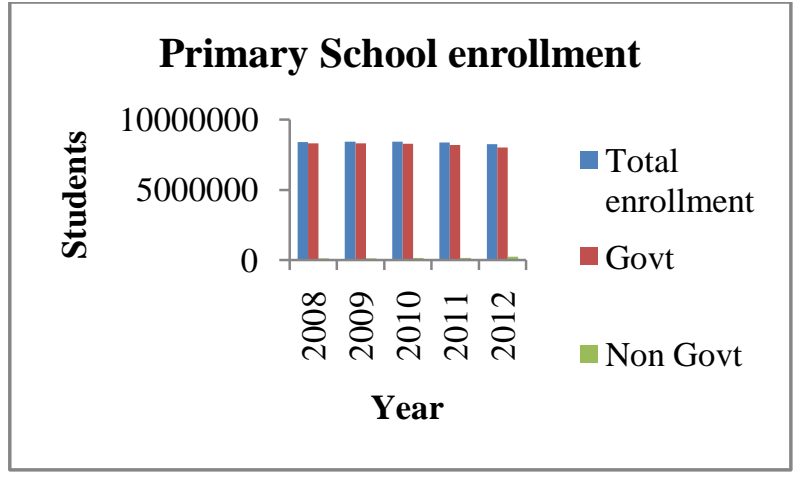

Figure 1 Primary School enrollment

\subsection{Primary School Completion}

Not all students enrolled in primary schools reach standard seven as shown in figure 2 below. There has been a fluctuating trend over the years. About $54.8 \%$ of 13 year-old children reached Standard VII in 2011. If pupil's retention in school is enhanced and enrolment is done at the official age, the completion rate will improve in the future.

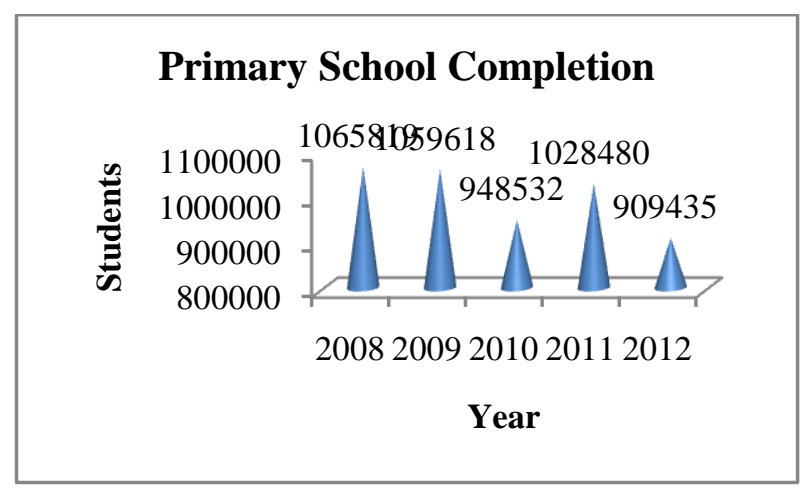

Figure 2 Primary school completion rate

\subsection{Teaching Staff}

Table 2 below shows the number of teachers in both government and non government schools. The teacher students' ratio between government and non government schools is also a factor to be addressed. The non government schools seem to have a good ratio compared to government schools. This is streamlined by the benefits, especially financial gains that teachers get from non government schools. Teachers categorized as qualified for primary education level are those with Grade A certificates and above [11]. An emphasis of using ICT in teaching has been put in the Teachers Education curriculum. The Grade A students have now been taught a course in ICT with the view of equipping them with the necessary skills to teach at primary schools. On the other hand the course is aimed to provide the opportunity of empowering teachers to improve their skills and knowledge in teaching and learning [12]. Almost all the Teachers college is equipped with necessary infrastructure including computers to deliver the courses in ICT.

Table 2: Teaching staff

\begin{tabular}{lccccc}
\hline \hline Year & 2008 & 2009 & 2010 & 2011 & 2012 \\
\hline Gov & 149,433 & 151,476 & 159,081 & 167,111 & 171,986 \\
Non Gov & 5,462 & 5,709 & 6,775 & 8,338 & 9,001 \\
Total & 154,895 & 157,185 & 165,856 & 175,449 & 180,987 \\
\hline \hline
\end{tabular}

\subsection{Survival Rates}

Not all students enrolled in standard One make it to standard Seven. Figure 3 below shows the percentage of survivals over the years. There is a fluctuation of the number of students who succeeded to be promoted to a next class. On the other hand some do not make it and they drop schools. Some of students repeat years for a number of reasons, one being a standard IV examination which necessitated a student to pass to be promoted to a next class.

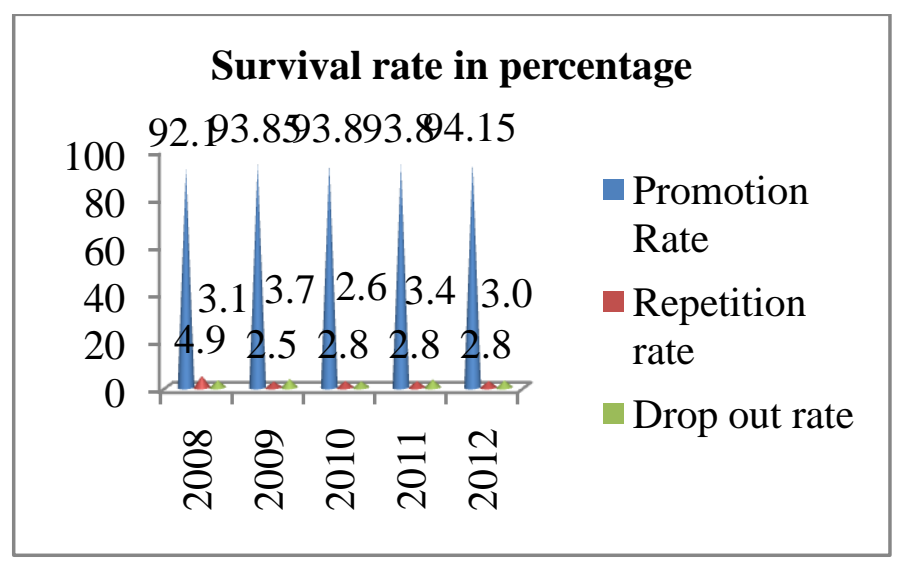

Figure 3 Survival rates

Of those who survive to Standard VII, not all of them join secondary education. Table 3 below shows, that for example in 2007 only about $56.8 \%$ of students were enrolled to Secondary education, which includes $51.2 \%$ from government primary schools and $5.6 \%$ from non government primary schools. The trend continues with $47 \%$ and $6.7 \%$ from government and non government respectively for the year 2011. This therefore implies that a good percent of students from primary schools do not make it to secondary education. Some of these opt for vocational education, non formal education or later go for adult education (figure 4) and to some this marks the end of the formal education.

Table 3: Standard VII leavers

\begin{tabular}{cc|cccccc}
\hline \hline & & \multicolumn{5}{c|}{ Enrolled to Form 1 } & \\
\hline \hline Year & Leavers & Govt & $\%$ & Non Govt & $\%$ & Total \\
\hline 2007 & 773,553 & 395,930 & 51.2 & 42,971 & 5.6 & 438,901 \\
2008 & $1,017,865$ & 480,529 & 47.2 & 44,255 & 4.3 & 524,784 \\
2009 & 999,070 & 382,207 & 38.3 & 56,620 & 5.7 & 438,827 \\
2010 & 894,889 & 403,873 & 45.1 & 63,282 & 7.1 & 467,155 \\
2011 & 973,812 & 457,321 & 47.0 & 65,058 & 6.7 & 522,379 \\
\hline
\end{tabular}




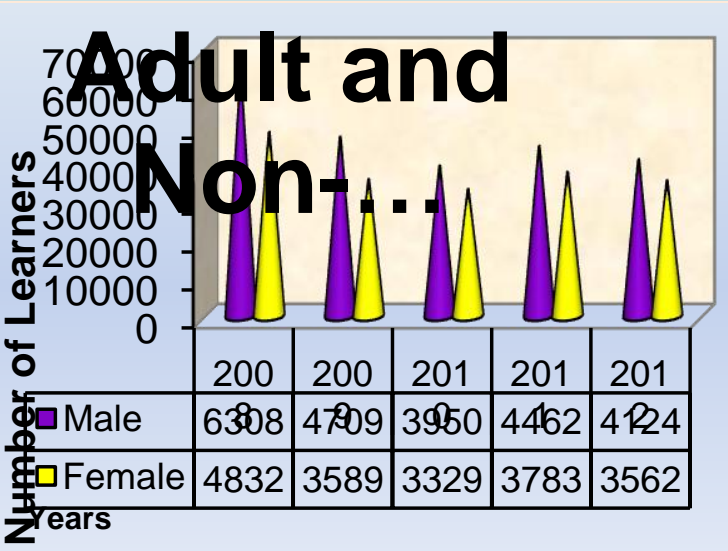

Figure 4 Adult and non formal education

The remaining portion of students can join the vocational training. In 2011/2012 for example 112447 students joined vocational training in various government and non government technical institutions in the country.

\subsection{Availability of Electricity}

By the year 2012, Tanzania had 180,987 primary schools (Table 1 above). Of these schools, 3409 schools had electricity, equivalent to $2 \%$ of the total number of schools. About $84 \%$ of these schools were connected to the National grid, figure 5, while some had other sources like Biogas, Solar power, generators, wind and some use small scale hydroelectric power.

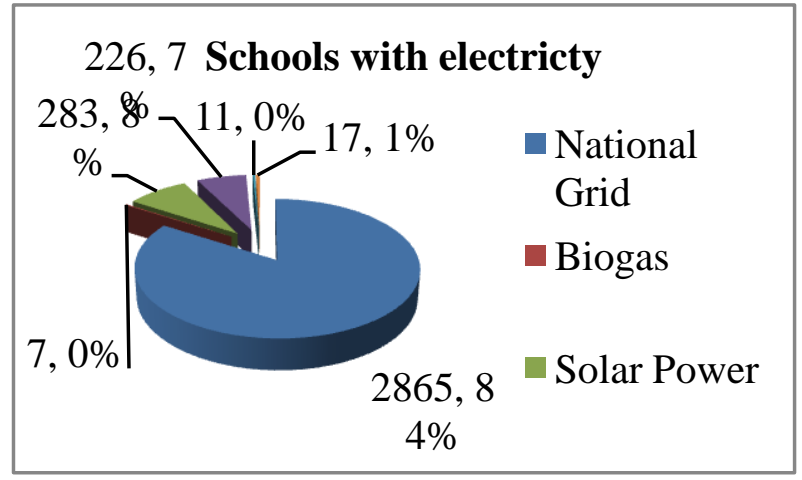

Figure 5 Sources of electrify

*Other Sources include Small Scale Hydroelectric power.

\subsection{Number of Computers}

A number of schools both government and non government are having computers for various uses. The total number of computers available in Tanzanian primary schools was 7,035. About $20 \%$ of these computers were possessed by government schools while the remaining $80 \%$ of the computers were owned by non government schools. This number includes both working and those which were not working. Figure 6 below illustrates this situation. It can clearly be shown that government schools which are many in number have fewer computers compared to non government schools. This ratio has a big impact to the quality of education to be delivered by these schools especially with regard to ICT.

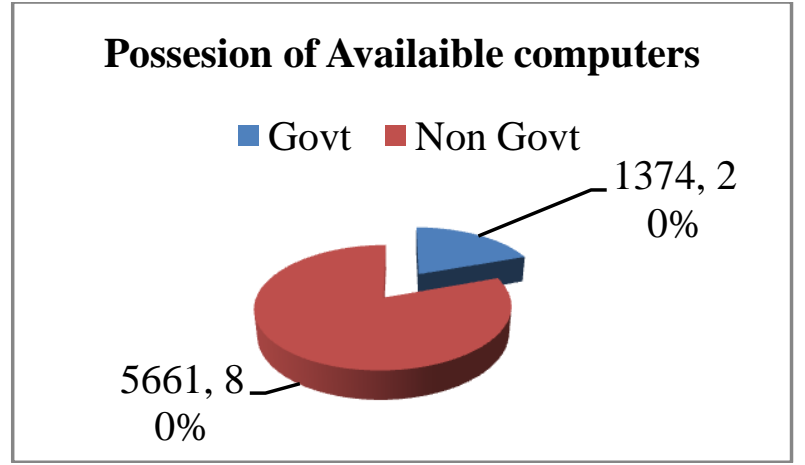

Figure 6 Possession of computers

Not all computers available in these schools are functioning. In non government schools for example, out of 5661 computers, 5626 computers are working equivalent to $99.4 \%$. in government schools, out of 1374 computers available, 1340 computers were working equivalent to $97.5 \%$. The figure 7 below illustrates.

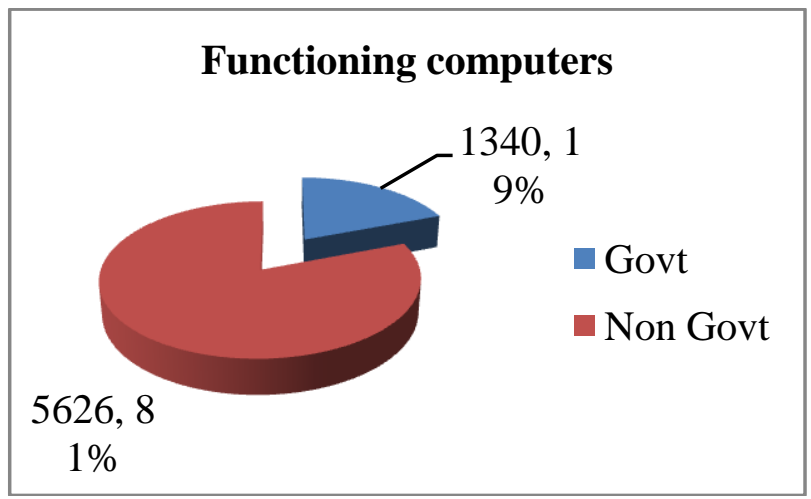

Figure 7 Functioning computers

\subsection{Use of Computers}

The computers available in these schools have various uses the main being for office use and Training. In non government schools for example in figure 8, out of 5626 computers, 1145 computers equivalent to $20 \%$ were used for office use, while the remaining $80 \%$ equivalent to 4481 computers were used for training purposes. In government schools, out of 1340 available working computers, 500 computers equivalent to $37.3 \%$ were used for office use while the remaining $62.7 \%$ equivalent to 840 computers were used for training.

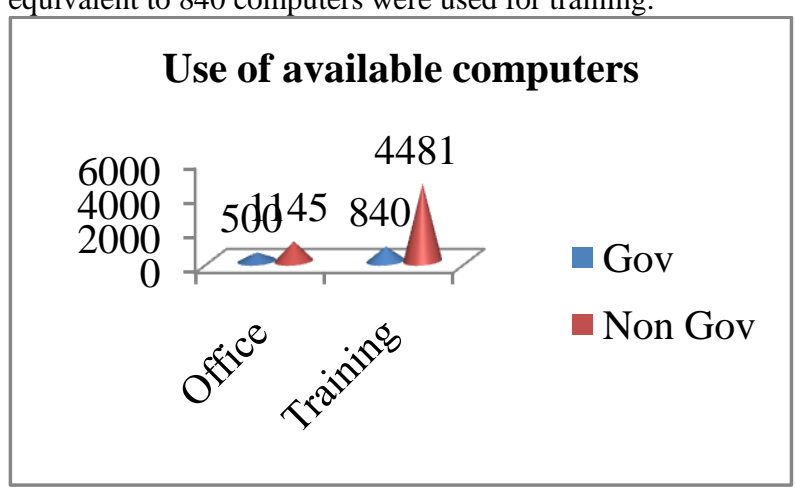

Figure 8 Use of available computers 


\section{DISCUSSIONS}

The data presented above shows that there is a big difference in the use of computer between government and non government schools. This situation calls for immediate actions for policy makers to balance the provision of quality education among citizens. Both the Tanzanian ICT policy of 2003 [6], the Basic Education ICT policy [1] recognizes the application of ICT in building a knowledgeable society. The Tanzania Vision 2025, a national strategy recognizes the role of education as a change agent in transforming societies to a knowledgeable economy. The Vision 2025 [14] also recognizes ICT as a tool to open up opportunities.

\subsection{Use of Computers in Education}

There have been a number of researches trying to figure out whether there is a need to use computers at lower levels such as primary schools. Some researchers were trying to find the best age to expose a child to computers [10]. What do schools want to solve with the use of computers, whether computerization should be made a priority, and the readiness of schools to adopt the computerization process [7][8]. Other issues include the access to electricity, internet and relevant knowledge on computing.

\subsection{Impact of the use of Computers in Education}

ICT, and the use of computers in particular has a good impact on the learning and the learners attitudes. There is evidence that the use of computers in classes has a good impact on children's knowledge, confidence, motivation and engagement towards the learning process. Numerous studies have found that both students and teachers that use computers have increased enthusiasm [13] . Therefore efforts already started by the Tanzanian government should be increased to increase the size of the learned society.

Balanskat [2] argues that in European primary schools, Teachers consider that ICT supports both „traditional teaching practices (exercises and practice, office tools) and more modern practices (self-directed learning, collaborative work); no differentiation in the assessment of teachers is found empirically.

Some $75 \%$ of primary teachers use computers in class - with a variation in rates from around $90 \%$ in the Nordic countries to around 35\% in Greece, Latvia and Hungary. Almost all of the teachers using ICT in class involve pupils in using the computers.

There is an amazingly widespread consensus about the positive impact of ICT among primary school teachers across Europe. About $87 \%$ say that pupils are more motivated and attentive; while only $21 \%$ believe that using computers in class does not have significant learning benefits.

\subsection{Improved ICT Infrastructure}

The existing infrastructure across the country makes it difficult to implement this initiative. While there is fiber backbone cable run across the country in almost every District head quarters, electricity becomes a big challenge.

There is no local manufacture of ICT equipment in Tanzania; all local dealers or agents import these products. There are also no standards guiding the imports of both hardware and software. There are few local companies are developing computer application packages.

\subsection{Digital Inclusion to the Drop Outs}

Education inequality among government and non government is witnessed from the data. While the ICT curriculum is already in place in Tanzania and the teachers are equipped from the capacity building program which allowed all Grade A teachers in all Teachers Training Colleges many government schools do not teach ICT. The number of computers and their use in government and non government schools tells this obvious inequality.

The data provided (Table 3 above) shows that there is a problem with Tanzanian students who lack the opportunity to go for further studies from primary education to miss the computer skills. There are initiatives in all around the country where computer classes are taught, in a number of small colleges (informal training centers) or in a form of workshops to just equip those with no knowledge in computing who wish to acquire some under some kind of fees. These classes range from training basic skills like office automation, internet and emails to basic maintenance, network administration or some software skills like computer graphics.

\subsection{Language and Internet Access}

Most of the non government primary school (sometimes called Academy, or English medium) use English as a media of instruction as opposed to government schools. The Tanzanian National language being Kiswahili, of course followed by English becomes another barrier to the adoption of computing to government schools. Most of the applications in computing are using English. Hence those from non government are advantaged over those from government although they also learn English as a subject.

In terms of internet connectivity, there is a great improvement though there are some places still unconnected. Tanzania has witnessed exponential growth in mobile phones applications. It is reported that most of the parts of the country has access to mobile phone connection, hence internet connectivity. This rapid development of the telecommunications market means that the cost of owning and using digital equipment across the country continues to decrease making ICT increasingly accessible to most of the average Tanzanian.

\subsection{Local Content}

Since English is only taught as a subject in schools and not a necessary medium of instruction in the country, then there is a big problem of finding the right local content that is in the language mostly used by children at primary level. Kiswahili is the major language spoken by most Tanzanians followed by native languages. It is therefore a necessity for Tanzanian scholars and other stakeholders to emphasize in generating local content. This will help in motivating children to grasp the use of technologies much faster and easier. The primary curriculum in ICT, called TEHAMA is now in Kiswahili, making an alert that more reference materials need to be generated to support this initiative. This has to go hand in hand with developing more applications in the language that is widely understood by the majority.

\subsection{ICT Policy Implementation}

Osin [8] argues that in the implementation of the the computerization in developing countries buying computers should not be the first activity. It is important to note that for ICT to enhance teaching and learning, it needs to be supported by education and school policies and effective professional development for teachers [15].To be successful in the implementation of such process then a number of activities needs to be taken in phases. Among other things, the phases 
should include creating cadres of instructors, Provide inservice training for teachers in the schools to be computerized, Introduce computers in teachers colleges, Plan experimental evaluations of all of the above and a also attract community support.

It's a high time that the government moves with the initiatives to include all citizens to get this knowledge. The teachers are already in place, but the infrastructures seem to be a big challenge, especially to government schools. The dependency on donors to promote this initiative may take longer than anticipated to implement. There has been an increasingly effort in providing electricity to most of the rural areas in the country through the Rural Energy agency, and the Power Africa project. These initiatives must be taken as catalysts in the implementation of this policy.

\subsection{Timing to Introduce the use of Computers}

There is a great debate of whether the primary level is the appropriate to introduce a child in the use of computers. Some argue that it is of no help to introduce a child to using technology at an early age since it might spoil the child's growth. Some are in favor of introducing a child at an early stage arguing that it is going to increase the innovation and thinking capability of these kids as they grow. However, the idea of introducing the kid to technology at an early age (primary education) has more advantages bearing in mind that the children need to have a mechanism of ensuring that they do not play around with unwanted programs. At this point, teachers, technical experts in ICT and parents need to take part in filtering the contents which children are supposed to access and at what extent.

\section{CONCLUSION}

The use of computer technology in education system especially primary level is unavoidable if the country wants to enhance innovation and creativity at early stages of the children growth. The equality and quality in education system provision should also be looked carefully. The education system should be provided equally and with skills that will help citizens to overcome the challenges they face in their daily lives. However, the introduction and use of computers in primary education should be taken carefully and be evaluated regularly to make sure that the anticipated objectives are achieved and trying to minimize the pitfalls to the learning process of children as there a lot of confusing stuffs in the use of computers if not properly taught to young generations.

\section{ACKNOWLEDGMENTS}

My thanks to the Ministry of Education and Vocational Training in Tanzania (MoEVT) for putting in public the annual Basic education Statistics for a better reflection of our Tanzanian education system.

\section{REFERENCES}

[1] ICT Policy for Basic Education, Ministry of Education and Vocational Training, Tanzania, 2007.

[2] Balanskat. A, 2007, Study of the impact of technology in primary schools Synthesis Report. STEPS

[3] Hare, H. 2007, ICT in Education in Tanzania, Infodev

[4] Education and Training Policy: Ministry of Education and Culture, Dar es Salaam, 1995

[5] P. Swats and E M Wachira, 2010,TANZANIA: ICT IN EDUCATION SITUATIONAL ANALYSIS, gesci.

[6] National ICT policy, 2003

[7] J. G. Ogembo, B.K Ngugi, M. Pelowski, Computerizing Primary Schools in Rural Kenya: Outstanding Challenges and Possible Solutions

[8] Luis Osin, Computers in Education in Developing Countries: Why and How?, Centre for Education Technolgy, Israel

[9] V. Dagiene, M. M. Sysło,2012, ICT in Primary Education Analytical survey Volume 1 Exploring the origins, settings and initiatives, UNESCO

[10] Cohen R.(2014), What Is The Right Age To Introduce Your Kids To Mobile Technology?, FORBES

[11] BEST 2012 National Data, Government of Tanzania, Ministry of Education and Vocational Tarining, Dar es Salaam

[12] ICT Academic Syllubus for Certificate course in Primary education (2009), Government of Tanzania, Ministry of Education and Vocational Tarining, Dar es Salaam

[13] Guide for Developing and Sustaining ICT in Primary Schools (2009), Vital Wave Consulting

[14] Basic Education Master Plan (Bemp) Medium Term Strategic And Programme Framework 2000-2005, (2001), Government of Tanzania, Ministry of Education and Culture, Dar es Salaam

[15] ICT in Primary Education Analytical survey, (2012), UNESCO 